\title{
Prediction and Context Awareness in Agriculture: A Systematic Mapping
}

Bruno Guilherme Martini, Gilson Augusto Helfer, Jorge Luis Victória Barbosa, Regina Célia Espinosa Modolo, Marcio Rosa da Silva, Rodrigo Marques de Figueiredo

University of Vale do Rio dos Sinos, São Leopoldo, Brazil

\begin{abstract}
The advances in sensorial technology and its use in agriculture have been contributing to the acquisition and analysis of data regarding agricultural production. Studies propose the use of sensors to monitor production or even the use of cameras to obtain crop information, providing data, reminders, and alerts to farmers. Through the obtainment and analysis of these data, context awareness can be used to improve systems, mainly through the prediction techniques applied to agriculture. This article presents a systematic mapping of studies that use prediction and context awareness in agriculture. During the mapping, 10206 articles were initially identified and, after filtering by inclusion and exclusion criteria, 42 articles were selected. The results indicated that $35.7 \%(15 / 42)$ of the studies used one or more prediction techniques and $45.2 \%$ (19/42) used image processing through pictures of cameras to obtain information regarding planting. 23 sensors with different functionalities were found, those have been used in the collection of data for context formation in agriculture.
\end{abstract}

\section{Keywords}

Technology for agriculture; systematic mapping; prediction in agriculture; context awareness in agriculture.

Martini, B. G., Helfer, G. A., Barbosa, J. L., Modolo, R. C. E., da Silva M. R. and de Figueiredo, R. M. (2020) "Prediction and Context Awareness in Agriculture: A Systematic Mapping", AGRIS on-line Papers in Economics and Informatics, Vol. 12, No. 3, pp. 45-58. ISSN 1804-1930. DOI 10.7160/aol.2020.120305.

\section{Introduction}

The advances in technology have been expanding agriculture's modernization. This modernization has been occurring mainly through the usage of embedded computers, development of sensors for the most diverse purposes related to agriculture and increased efficiency and reliability in the communication between electronic devices. Thus, agriculture is adopting technological resources designed to increase performance from planting to harvesting.

These technological advances culminated in increased productivity and immunity of the planted crops. A factor that drives the pursuit for increased agricultural productivity is that approximately $70 \%$ of the available fresh water is consumed by the agricultural sector (Pimentel et al., 2004). Therefore, increasing the efficiency of agriculture becomes strategic, fomenting public and private investments in this sector. Through more assertive equipment and the possibility to obtain data that was not possible years ago, agriculture began to be called Precision Agriculture (Manzatto et al., 1999). Along these lines, technology has been applied in the detection of pests and diseases, planting failures, excessive irrigation, support and monitoring of the harvest and assistance to the demarcation of planting and controlled sprays.

As information on crops become increasingly accessible, studies on context awareness (Dey et al., 2001) and prediction (Nagini et al., 2016) are being developed more frequently by the scientific community. Context means any information that characterizes objects, environment or people. The process of obtaining this information must occur without the user having to take any action, that is, it must occur automatically. Context awareness refers to computational systems that induce actions or perform operations to improve the usability in environments and systems. Prediction can be defined as the act or effect of affirming something that will occur in the future, as approached by Nagini et al (2016). 
Regarding methodology, this article uses systematic mapping which, according to Petersen et al. (2015), eliminates or reduces the differences that may exist when compared to revisions that do not have a determined method and with expressive results. Therefore, it is possible to obtain more reliable results and a greater impact. This study allows showing the techniques and technologies most used for prediction and context awareness applied in agriculture.

This work also aims, based on the literature analyzed, to present possible research gaps and challenges. This way, this article proposal is to present the state of the art, supporting future researches. The motivation of this study is to find out which are the most relevant databases for research in the area of prediction and context awareness in agriculture. In addition, to discover who are the main authors of the area, which are the most important works, the most used sensors, the used techniques of prediction, the deficiencies and the challenges of the area in order to assist future research.

\section{Materials and methods}

Through the use of a systematic mapping methodology, not only a final conclusion is discussed, but all the activities related to the discoveries throughout the mapping process are debated. Thus, the systematic mapping is able to make the connection between the data collection, the places where the articles were published, the area of application in agriculture, the year of publication of the studies, technologies that were used, which methodology was used in their development, among other information. The mapping focuses on published articles, which may be published in newspapers, conferences, books, and workshops. The steps for mapping are: a) elaboration of the research questions; b) elaboration of the search process and c) definition of the criteria to filter the results.

\section{Research questions}

For this work, research questions were defined and organized into three general questions (GQ), two specific questions (SPQ) and two statistical questions (STQ). The purpose of the general questions is to understand in what areas of agriculture context awareness and/or prediction are applied, what technologies are currently used and how information is communicated between sensors and servers. The objective of the specific questions is to identify the studies that use cameras to obtain information, which systems use prediction applied in agriculture and which technique is used in each of them. Finally, the goal of the statistical questions is to gather data on the studied area and show the behavior of publications over the last 10 years. The technologies used for context awareness and prediction in agriculture were hardly applied before 2008, therefore, the year 2008 served as a limit. The research questions are detailed in Table 1.

\begin{tabular}{|l|l|}
\hline Type & Details \\
\hline General Questions \\
\hline GQ 1 & $\begin{array}{l}\text { Which context-aware computing technologies } \\
\text { are being used in agriculture? }\end{array}$ \\
\hline GQ 2 & $\begin{array}{l}\text { Is the information sent via cable } \\
\text { or by what type of wireless network? }\end{array}$ \\
\hline GQ 3 & $\begin{array}{l}\text { Which areas of agriculture are applying } \\
\text { context awareness } \\
\text { and/or prediction? }\end{array}$ \\
\hline Specific Questions \\
\hline SPQ 1 & $\begin{array}{l}\text { Which works use cameras to obtain } \\
\text { information in agriculture? }\end{array}$ \\
\hline SPQ 2 & $\begin{array}{l}\text { Which prediction techniques are used } \\
\text { in agriculture? }\end{array}$ \\
\hline Statistical Questions \\
\hline STQ1 & Where were the researches published? \\
\hline STQ 2 & How many publications per year? \\
\hline
\end{tabular}

Source: author

Table 1: Research questions.

\section{Elaboration of the search process}

The search process was organized in three stages: specify the search string, select the databases and understand the search method of each one of them and, finally, obtain the results of the research. For the first stage, it was adopted the research process proposed by Kai Petersen (2015). The first stage identifies the main terms and their most relevant synonyms. In this study, the term "Agriculture" was selected as the primary term and as secondary the terms "Context Prediction", "Context Awareness", "Cyber-Physical System" and "Internet of Things". The synonyms for Agriculture were words that refer to methods of planting regarding indoor agriculture (hydroponics and aquaponics), to ensure that it would also be obtained studies applied in greenhouses or pavilions, as there are specific methods for internal planting. For the secondary terms, acronyms of the original terms or synonyms were used, as shown in Table 2.

Once the terms and synonyms were defined, the following search string was elaborated: 


\begin{tabular}{|l|l|}
\hline \multicolumn{2}{|c|}{ Search String Terms } \\
\hline Main Terms & Synonyms \\
\hline Agriculture & "agriculture" OR "hydroponics" OR "aquaponics" \\
\hline Context Predicton & "context prediction" OR "prediction of context" \\
\hline Cyber Physical System & "cyber physical system" OR "cps" \\
\hline Context Awarness & "context awareness" OR "context aware" \\
\hline Internet of Things & "IoT" OR "Internet of Things" \\
\hline Source: author &
\end{tabular}

Table 2: Search terms.

(("agriculture" OR "hydroponics" OR "aquaponics") AND ("context prediction" OR "prediction of context" OR "cyber physical system" OR "cps" OR "context awareness" OR "context aware" OR "IoT" OR "Internet of Things")). With the search string defined, the second step was to select databases that were relevant to the study area to apply the string. As each base has its search method, after selecting them it was necessary to determine the search parameters to be used in each one. Thus, four research databases were used, including the ACM Digital Library, IEEE Xplore, Science Direct and Springer Link.

The selected databases are the ones that prioritize research studies in the area of computer science since the mapping has as an emphasis on context awareness and prediction applied in agriculture. Therefore, articles from the field of agriculture could enter the selection, but when going through the filtering criteria would be withdrawn if they didn't have any link to context awareness or prediction.

The search in the ACM Digital Library database required the use of advanced search features, in which the search string was entered into the edit field of the database itself. For the search in the IEEE Xplore database, it was also used the advanced search feature. The search process in the Science Direct repository involved the application of the string to the title, abstract, and keywords. Lastly, in the Springer Library, in addition to using the search string as the query, it was also necessary to remove documents categorized as "Preview Only". After the exclusion of these files, the search filter "Computer Science" was selected first, the search was carried out and the "Life Science" filter was selected for results that could also be linked to the searched topic.

\section{Definition of the criteria to filter the results}

A few criteria were defined to include and exclude works obtained from the databases. Therefore, the Inclusion Criteria (IC) and Exclusion Criteria (EC) were defined as follows:

- IC 1: The study must be published in a journal, conference or workshop.

- IC 2: The study must be a full paper.

- IC 3: The study must be related to computer science or life science areas.

The Exclusion Criteria (EC) are the following:

- EC 1: Studies published before 2008.

- EC 2: Studies that were not written in English.

- EC 3: Studies that were published in theses and journals.

- EC 4: Studies that do not present a connection between agriculture and computer science.

- EC 5: Studies that are not related to the search questions.

The inclusion and exclusion criteria assist during the filtering process in order to obtain works that are more adherent to the study and to eliminate discrepancies generated in the research. Due to the filtering, impurities that did not meet the inclusion criteria were removed, this being the first step in the filtration. The number of studies obtained in each step of the filtering and the percentages of work withdrawn in each step can be seen in Figure 1.

After the articles were filtered in the initial search through the string and after having passed the first 2 IC, they went to the third filtering. The third mapping filter was the withdrawal of studies due to the first three exclusion criteria. Next, the works were filtered by title and keywords. In the fifth filtering step, the studies were removed after reading the abstract. Then the duplicate articles were removed.

At the end of the filtering process, a complete reading of each article was performed, observing the last two exclusion criteria (EC 4 and EC 5). Figure 1 presents the filtering process, 


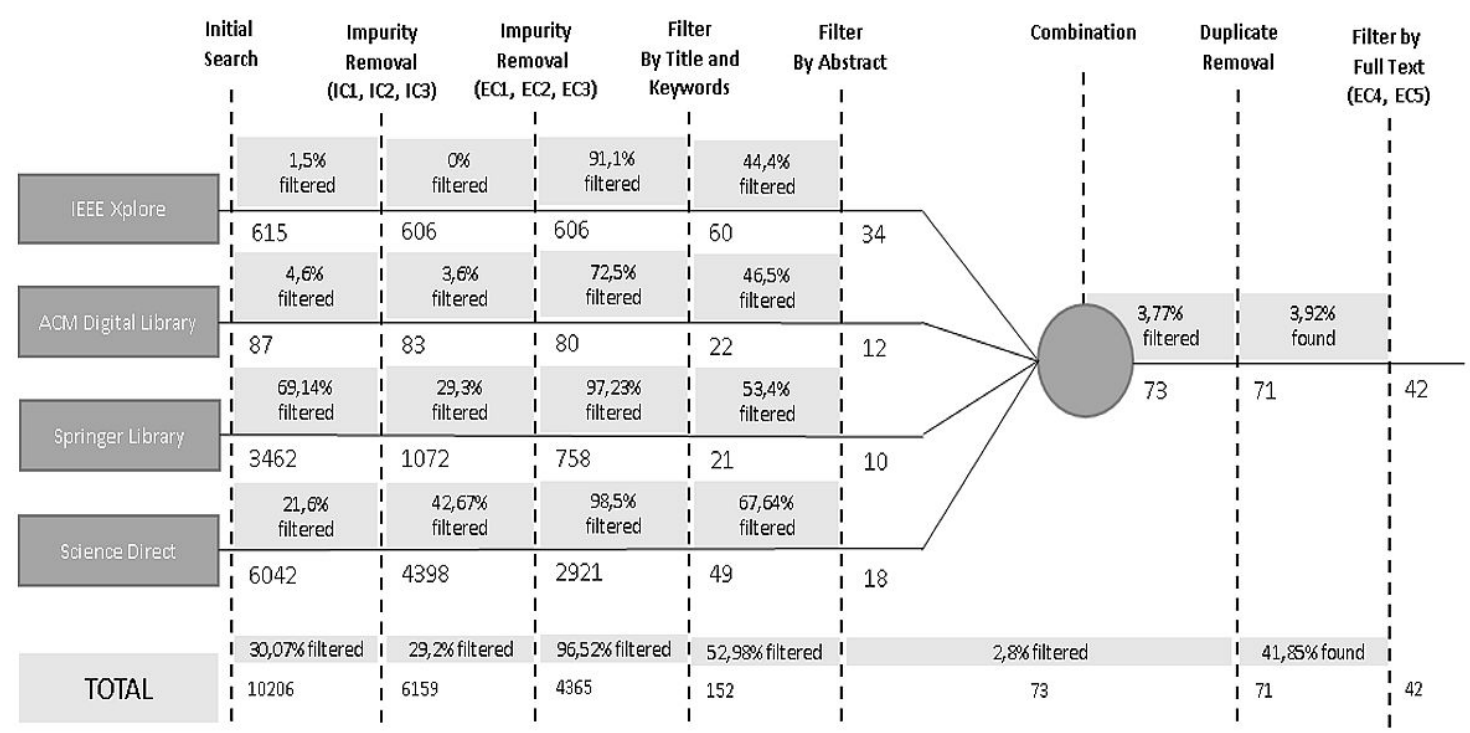

Source: author

Figure 1: Complete filtering of systematic mapping.

with the Inclusion Criteria and Exclusion Criteria applied in each step. The IEEE Xplore and ACM databases presented fewer articles. However, these bases were more assertive, considering the percentage between the number of articles found in the initial research until their combination after reading by abstract. Considering that the Springer Library and Science Direct databases had more than $99 \%$ of the results filtered along the process, it can be concluded that, although they have brought more results when compared with the other databases, the searches originated fewer articles that were adhering to the proposed theme.

\section{Results and discussion}

In this section, the results obtained by reading and analyzing the 42 mapped studies are presented. The research questions were answered and additional considerations and analysis on the studies were presented.

\section{GQ 1: Which context-aware computing} technologies are being used in agriculture?

The articles were classified according to the type of microcontrollers that they use in the systems, as well as the types of sensors that are being used to obtain the context information of the plantations. In the studies, the two most used microcontrollers are Raspberry and Arduino. Table 3 shows that they are used in 50\% (21/42) of the works. Not all articles in the systematic mapping used microcontrollers.
However, some studies used two microcontrollers (Kumar et al., 2016; Popovic et al., 2017; Goap et al., 2018; Mehra et al., 2018).

Table 4 presents the sensors that were used to obtain planting information. The types of sensors were of the most diverse functionalities, totaling 23 types. Not all sensors with the same functionality are identical, for example, among the moisture sensors the sensor SHT11 was applied in the study by Santos et al. (2018) and the DHT11 sensor in the study by Kumar et al. (2016). Thus, it is possible to obtain information even with different sensor models. As the purpose of this mapping is to inform what information and variables are being obtained and not to indicate exactly which sensors are being applied in each study, only the kind of sensors used by each one of the studies was indicated. 


\begin{tabular}{|l|c|c|l|}
\hline Microcontroller & Number of articles & Percentage & \multicolumn{1}{c|}{ Article's ID } \\
\hline ARM & 1 & $2.4 \%$ & (Kubicek et al., 2013) \\
\hline Arduino & 11 & $26.4 \%$ & $\begin{array}{l}\text { (Fukatsu, 2014), (Patil and Thorat, 2016), (Kumar et al., 2016), } \\
\text { (Rajendrakumar and Parvati, 2017), (Popovic' et al., 2017), (Saha } \\
\text { et al., 2017), (Athani and Tejeshwar, 2017), (Rodríguez } \\
\text { et al., 2017), (Santos et al, 2018), (Goap et al, 2018), (Mehra } \\
\text { et al., 2018) }\end{array}$ \\
\hline Intel Galileo Gen2 & 1 & $2.4 \%$ & (Ivanov and Tsvetkov, 2017) \\
\hline Raspberry & 14 & $33.3 \%$ & $\begin{array}{l}\text { (Rodriguez et al., 2014), (Kumar et al., 2016), (Alipio et al., } \\
\text { 2017), (Eko et al., 2017), (Popovic' et al., 2017), (Arakeri et al., } \\
\text { 2017), (Kuangdhar et al., 2017) (Kokkonis et al., 2017), (Jacob, } \\
\text { 2018), (Mehra et al., 2017), (Park et al., 2017), (Goap et al, }\end{array}$ \\
\hline Zigbee & 6 & $14.4 \%$ & $\begin{array}{l}\text { (Zhou et al., 2011), (Divya et al., 2014), (Patil and Thorat, 2016), } \\
\text { (Zhang et al., 2017), (Rodríguez et al., 2017), (Zhou and Li, 2017) }\end{array}$ \\
\hline
\end{tabular}

Source: author

Table 3: Relation of the used microcontrollers.

\begin{tabular}{|c|c|c|c|}
\hline Sensors & Number of articles & Percentage & Article's ID \\
\hline Soil Moisture & 22 & $52.4 \%$ & $\begin{array}{l}\text { (Zhou et al., 2011), (Zhou et al., 2012), (Divya et al., 2014), } \\
\text { (Rodriguez et al., 2014), (Tan and Tan, 2016), (Patil and Thorat, } \\
\text { 2016), (Carrasquilla-Batista et al., 2016), (Ivanov and Tsvetkov, } \\
\text { 2017), (Rajendrakumar and Parvati, 2017), (Zhang et al., 2017), } \\
\text { (Popovic' et al., 2017), (Saha et al., 2017), (López-Riquelme et } \\
\text { al., 2017), (Athani and Tejeshwar, 2017), (Rodríguez et al., 2017), } \\
\text { (Sarangdhar et al., 2017), (Zhou and Li, 2017), (Kokkonis et al., } \\
\text { 2017), (Joshi et al., 2017), (Park et al., 2017), (Goap et al., 2018), } \\
\text { (Huong et al., 2018) }\end{array}$ \\
\hline Water Temperature & 6 & $14.3 \%$ & $\begin{array}{l}\text { (Shahriar and Mcculluch, 2014), (Xu et al., 2014), (Alipio et al., } \\
\text { 2017), (Eko et al., 2017), (Jacob, 2017), (Santos et al., 2018) }\end{array}$ \\
\hline $\begin{array}{l}\text { Environmental } \\
\text { Temperature }\end{array}$ & 18 & $42.8 \%$ & $\begin{array}{l}\text { (Zhou et al., 2011), (Zhou et al., 2012), (Kubicek et al., 2013), } \\
\text { (Tan et al., 2015), (Patil and Thorat, 2016), (Kumar et al., 2016), } \\
\text { (Carrasquilla-Batista et al., 2016), (Ivanov and Tsvetkov, 2017), } \\
\text { (Rajendrakumar and Parvati, 2017), (Eko et al., 2017), (Popovic' } \\
\text { et al., 2017), (Saha et al., 2017), (Rodríguez et al., 2017), (Sarangdhar } \\
\text { et al., 2017), (Zhou and Li, 2017), (Joshi et al., 2017), (Goap et al., } \\
\text { 2018), (Plazas et al., 2018) }\end{array}$ \\
\hline Luminosity & 12 & $28.6 \%$ & $\begin{array}{l}\text { (Zhou et al., 2011), (Zhou et al., 2012), (Tan et al., 2015), } \\
\text { (Carrasquilla-Batista et al., 2016), (Ivanov and Tsvetkov, 2017), } \\
\text { (Alipio et al., 2017), (Eko et al., 2017), (Rodríguez et al., 2017), } \\
\text { (Zhou and Li, 2017), (Joshi et al., 2017), (Park et al., 2017), (Plazas } \\
\text { et al., 2018) }\end{array}$ \\
\hline $\mathrm{CO} 2$ & 4 & $9.6 \%$ & $\begin{array}{l}\text { (Zhou et al., 2011), (Zhou et al., 2012), (Zhou and Li, 2017), (Park } \\
\text { et al., 2017) }\end{array}$ \\
\hline Soil Chemicals & 7 & $16.7 \%$ & $\begin{array}{l}\text { (Zhou et al., 2012), (Kubicek et al., 2013), (Divya et al., 2014), (Tan } \\
\text { et al., 2015), (Kumar et al., 2016), (Popovic' et al., 2017), (Park et al., } \\
\text { 2017) }\end{array}$ \\
\hline Soil's temperature & 8 & $19 \%$ & $\begin{array}{l}\text { (Zhou et al., 2011), (Zhou et al., 2012), (Kubicek et al., 2013), (Divya } \\
\text { et al., 2014), (Rodriguez et al., 2014), (Tan et al., 2015), (López- } \\
\text { Riquelme et al., 2017), (Goap et al., 2018) }\end{array}$ \\
\hline $\begin{array}{l}\text { Environmental } \\
\text { humidity }\end{array}$ & 17 & $40.5 \%$ & $\begin{array}{l}\text { (Zhou et al., 2011), (Zhou et al., 2012), (Kubicek et al., 2013), } \\
\text { (Tan et al., 2015), (Patil and Thorat, 2016), (Kumar et al., } \\
\text { 2016), (Carrasquilla-Batista et al., 2016), (Alipio et al., 2017), } \\
\text { (Rajendrakumar and Parvati, 2017), (Eko et al., 2017), (Saha et al., } \\
\text { 2017), (Rodríguez et al., 2017), (Sarangdhar et al., 2017), (Zhou } \\
\text { and Li, 2017), (Santos et al., 2018), (Goap et al., 2018), (Plazas et al., } \\
\text { 2018) }\end{array}$ \\
\hline
\end{tabular}

Source: author

Table 4: Relation of the used sensors. 


\begin{tabular}{|l|l|l|l|}
\hline Sensors & $\begin{array}{l}\text { Number of } \\
\text { articles }\end{array}$ & Percentage & Article's ID \\
\hline $\begin{array}{l}\text { Atmospheric } \\
\text { pressure }\end{array}$ & 2 & $4.8 \%$ & (Popovic' et al., 2017), (Plazas et al., 2018) \\
\hline Wind Speed & 2 & $4.8 \%$ & (Popovic' et al., 2017), (Plazas et al., 2018) \\
\hline Rain & 2 & $4.8 \%$ & (Shahriar and Mcculluch, 2014), (Popovic' et al., 2017) \\
\hline RFID & 1 & $2.4 \%$ & (Kubicek et al., 2013) \\
\hline Soil's pH & 2 & $4.8 \%$ & (Zhou et al., 2011), (Divya et al., 2014) \\
\hline Salinity & 2 & $4.8 \%$ & (Shahriar and Mcculluch, 2014), (Xu et al., 2014) \\
\hline Dissolved oxygen & 1 & $2.4 \%$ & (Xu et al., 2014) \\
\hline Water Conductivity & 3 & $7.2 \%$ & $\begin{array}{l}\text { (Carrasquilla-Batista et al., 2016), (Alipio et al., 2017), (Eko et al., } \\
\text { 2017) }\end{array}$ \\
\hline UV & 2 & $4.8 \%$ & (Goap et al., 2018), (Plazas et al., 2018) \\
\hline Solenoid & 1 & $2.4 \%$ & (Kokkonis et al., 2017 \\
\hline Thermohygrometer & 1 & $2.4 \%$ & (Plazas et al., 2018) \\
\hline Water Level & 5 & $12 \%$ & $\begin{array}{l}\text { (Shahriar and Mcculluch, 2014), (Carrasquilla-Batista et al., 2016), } \\
\text { (Sarangdhar et al., 2017), (Jacob, 2017), (Mehra et al., 2018) }\end{array}$ \\
\hline Water's pH & 8 & $\begin{array}{l}\text { (Xu et al., 2014), (Carrasquilla-Batista et al., 2016), (Alipio et al., } \\
\text { 2017), (Rajendrakumar and Parvati, 2017), (Eko et al., 2017), (Saha } \\
\text { et al., 2017), (Athani and Tejeshwar, 2017), (Mehra et al., 2018) }\end{array}$ \\
\hline Ultrasonic & 1 & $19 \%$ & (Arakeri et al., 2017) \\
\hline
\end{tabular}

Source: author

Table 4: Relation of the used sensors.

GQ 2: Is the information sent via cable or by what type of wireless network?

The transmission of the information basically involves three types of communication: Wi-Fi, mobile data $(3 \mathrm{G} / 4 \mathrm{G})$ and cable. In this systematic mapping, the Wi-Fi communication was considered as all that wireless communication that does not communicate data through GPRS/ GSM modules. This Wi-Fi communication can be between the dispersed microcontrollers in the planting and a server, the communication between the microcontrollers, among others. Table 5 shows the types of communication, and which studies use each type and how many studies use each transmission type.

\section{QG 3: Which areas of agriculture are applying context awareness and/or prediction?}

Indoor agriculture is defined as the agriculture held in an enclosed location, such as a plantation inside a greenhouse or pavilion. In this type of culture, 11 studies were found. Outdoor agriculture is applied in open environments where the possibility of environmental control is reduced. For this type of cultivation 21 studies were found, which are distributed throughout the period of the mapping, since there are studies from 2009 to 2018 .

The term agriculture has been used for studies that can be applied to both indoor and outdoor agriculture. Table 6 shows the areas where the studies were applied. Since in the indoors agriculture there are different cultivation methods, Table 6 considers separately the traditional method of indoor agriculture as specifically three alternative types of indoor agriculture, namely, Aquaculture, Hydroponics and Aquaponic.

Hydroponics is a model of agriculture cultivation that works by recirculating water that has the necessary nutrients for the plants, it is used in closed places, such as greenhouses or pavilions. Prediction and context awareness studies in hydroponics have recently begun in 2017 with the studies of Alipio et al. (2017) and Eko et al. (2017) and in 2018 the study by Mehra et al. (2018) was published. It was also found two studies on aquaculture, that is fish farming with control over water quality (Shahriar and Mcculluch, 2014; $\mathrm{Xu}$ et al., 2014). In aquaponics was found only one study of Jacob (2017).

Among the areas of application are the studies on outdoor agriculture, always in greater numbers during the years. However, the number of studies applied in indoor agriculture increased substantially, 8 studies in the years 2017 and 2018 against 2 studies published in 2015 and 2016. Ontheotherhand, outdooragriculture grewassociated with the same period at a rate lower (15 studies against 5 studies) than indoor agriculture, 


\begin{tabular}{|c|c|c|c|}
\hline $\begin{array}{l}\text { Type of } \\
\text { communication }\end{array}$ & $\begin{array}{l}\text { Number } \\
\text { of articles }\end{array}$ & Percentage & Article's ID \\
\hline Wired & 3 & $7.2 \%$ & (Zhang et al., 2017), (Joshi et al., 2017), (Mehra et al., 2018) \\
\hline Mobile Data & 14 & $33.3 \%$ & $\begin{array}{l}\text { (Luimula and Shelby, 2009), (Zhou et al., 2012), (Kubicek } \\
\text { et al., 2013), (Divya et al., 2014), (Rodriguez et al., 2014), (Xu et al., } \\
\text { 2014), (Carrasquilla-Batista et al., 2016), (Ivanov and Tsvetkov, 2017), } \\
\text { (Zhang et al., 2017), (Popovic' et al., 2017), (Saha et al., 2017), (Zhou } \\
\text { and Li, 2017), (Kokkonis } \\
\text { et al., 2017), (Plazas et al., 2018) }\end{array}$ \\
\hline Wi-Fi & 24 & $57.1 \%$ & $\begin{array}{l}\text { (Luimula and Shelby, 2009), (Zhou et al., 2011), (Zhou } \\
\text { et al., 2012), (Kubicek et al., 2013), (Fukatsu, 2014), (Divya et } \\
\text { al., 2014), (Rodriguez et al., 2014), Rupanagudi et al., 2015), (Tan } \\
\text { et al., 2015), (Kumar et al., 2016), (Ivanov and Tsvetkov, 2017), } \\
\text { (Rajendrakumar and Parvati, 2017), (Eko } \\
\text { et al., 2017), (Zhang et al., 2017), (Athani and Tejeshwar, 2017), } \\
\text { (Rodríguez et al., 2017), (Sarangdhar et al., 2017), (Zhou and Li, } \\
\text { 2017), (Jacob, 2017), (Joshi et al., 2017), (Park et al., 2017), (Santos } \\
\text { et al., 2018), (Goap et al., 2018), (Fiehn et al., 2018) }\end{array}$ \\
\hline
\end{tabular}

Source: author

Table 5: Type of communication of the prototypes.

\begin{tabular}{|l|c|c|l|}
\hline Agriculture Area & $\begin{array}{c}\text { Number } \\
\text { of articles }\end{array}$ & Percentage & \multicolumn{1}{c|}{ Article's ID } \\
\hline Agriculture & 8 & $19 \%$ & $\begin{array}{l}\text { (Divya et al., 2014), (Janaszek, 2016), (Rajendrakumar and Parvati, 2017), } \\
\text { Yahata et al., 2017), (Zhang et al., 2017), (Popovic' et al., 2017), (Zhou } \\
\text { and Li, 2017), (Huong et al., 2018) }\end{array}$ \\
\hline Outdoor agriculture & 21 & $50 \%$ & $\begin{array}{l}\text { (Luimula and Shelby, 2009), (Zhou et al., 2011), (Kubicek et al., 2013), } \\
\text { (Fukatsu, 2014), (Rodriguez et al., 2014), (Rupanagudi et al., 2015), (Tan } \\
\text { et al., 2015), (Tan and Tan, 2016), (Patil and Thorat, 2016), (Kumar et al., } \\
\text { et al., 2017), (Arakeri et al., 2017), (Sarangdhar et al., 2017), (Kokkonis } \\
\text { et al., 2017), (Joshi et al., 2017), (Goap et al., 2018), (Plazas et al., 2018), } \\
\text { (Treboux and Genoud, 2018), (Fiehn et al., 2018) }\end{array}$ \\
\hline Indoor agriculture & 7 & $16.7 \%$ & $\begin{array}{l}\text { (Zhou et al., 2012), (Ma et al., 2015), (Carrasquilla-Batista et al., 2016), } \\
\text { (Athani and Tejeshwar, 2017), (Rodríguez et al., 2017), (Park et al., 2017), } \\
\text { (Santos et al., 2018) }\end{array}$ \\
\hline Aquaculture & 2 & $4.8 \%$ & (Shahriar and Mcculluch, 2014), (Xu et al., 2014) \\
\hline Hydroponics & 3 & $7.2 \%$ & (Alipio et al., 2017), (Eko et al., 2017), (Mehra et al., 2018) \\
\hline Aquaponic & 1 & $2.4 \%$ & (Jacob, 2017) \\
\hline
\end{tabular}

Source: author

Table 6: Areas of agriculture in which the studies have been applied.

but continues to have higher final numbers. This growth of indoor agriculture has generated a balance between areas over the past two years. The two studies on aquaculture (Shahriar and Mcculluch, 2014; Xu et al., 2014) were published in 2014.

\section{SPQ 1: Which works use cameras to obtain information in agriculture?}

During the mapping, 19 articles that use cameras to obtain information about the production process were found. Among them, the studies of Zhou and Li (2017) and Jacob (2017) used the cameras to visualize the plantation, that is, production information was not obtained beyond the visualization of the crop. Other 17 studies (Luimula and Shelby, 2009; Zhou et al., 2012;
Kubicek et al., 2013; Fukatsu, 2014; Rodriguez et al., 2014; Rupanagudi et al., 2015; Ma et al., 2015; Tan et al., 2016; Kumar et al., 2016; Janaszek, 2016; Yahata et al., 2017; Zhang et al., 2017; Arakeri et al., 2017; Sarangdhar et al., 2017; Joshi et al., 2017; Treboux and Genoud, 2018; Fiehn et al., 2018) obtained information for several functionalities, among them, detection of pests in the plantation, identification of fruits with problems in their formation, insect count, plants growth, among others.

The cameras used in the studies have the function of taking pictures. The information taken from the images is provided by other devices, applications and programs through image 
processing. Image processing is getting more and more expressive results, as is evident in the studies of this mapping. Images of plantings were analyzed in different ways in the studies and provided information such as detecting plant species indication (Kumar et al., 2016), plant sizes (Joshi et al., 2017) and (Fukatsu, 2014), plague on fruits (Tan et al., 2016), indication of bird species (Fiehn et al., 2018), insect count (Fukatsu, 2014), fruit color (Tan et al., 2016), among other aspects. These applications show the potential in the area because of the diversity of information that can be obtained with the same equipment.

\section{SPQ 2: Which prediction techniques are used in agriculture?}

Predictive systems avoid losses, for they avoid the non-ideal zone of execution of the system, but in return, a more comprehensive monitoring of information is required, as well as a forecast model. Thus, prediction software depends on the generation of a predictive model based on data analysis, such as the context that it is included. Table 7 shows the 16 works that use the prediction in agriculture, highlighting the technique applied in each of them. Some articles use more than one technique and for that reason when adding the used techniques, their value is greater than the number of studies.

Table 7 shows that there are studies that applied two or even three prediction techniques. Park et al. (2017) applied three techniques and then reported which one got the best result. The works of Shahriar and Mcculluch (2014), Janaszek (2016), Patil and Thorat (2016) and Rodríguez et al. (2017) applied two prediction techniques.

\section{STQ 1: Where were the researches published?}

The articles were grouped according to the four databases that were used in the research. The base that obtained the largest number of papers was the IEEE Xplore with 16 articles out of a total of 42 , or $38 \%$. In second place was the Science Direct database with 12 articles, resulting in $28.5 \%$. The ACM Digital Library database returned 8 studies (19\%) and finally, the Springer Library returned 6 articles, the equivalent to $14.3 \%$. The Figure 2 shows the 42 articles distributed per year of publication and database.

\section{STQ 2: How many publications per year?}

Over the past two years, the number of publications on prediction and/or context awareness has increased significantly. This growth shows the interest of researchers in applying prediction and contexts to improve the cultivate in agriculture as well as the quality of products through the better monitoring of production. It is also possible to verify that the database that was most present in these 10 years of studies was the Science Direct, because in 7 of 10 years there were articles selected. From 2014, there was a greater diversity of the databases until 2017. In 2018 the Springer Library database was the only one that had no articles selected for the mapping.

\begin{tabular}{|l|c|c|l|}
\hline Agriculture area & $\begin{array}{c}\text { Number of } \\
\text { articles }\end{array}$ & Percentage & \multicolumn{1}{c|}{ Article's ID } \\
\hline Expert Rules & 1 & $2.4 \%$ & (Shahriar and Mcculluch, 2014) \\
\hline Time Series & 1 & $2.4 \%$ & (Shahriar and Mcculluch, 2014) \\
\hline Linear/Vector Regression & 3 & $7.2 \%$ & $\begin{array}{l}\text { (Rodríguez et al., 2017), (Sarangdhar et al., 2017), (Goap et al., } \\
\text { 2018) }\end{array}$ \\
\hline Neural Networks & 5 & $12 \%$ & $\begin{array}{l}\text { (Athani and Tejeshwar, 2017), (Rodríguez et al., 2017), (Park et } \\
\text { al., 2017), (Mehra et al., 2018), (Plazas et al., 2018) }\end{array}$ \\
\hline Statistical Method & 1 & $2.4 \%$ & (Patil and Thorat, 2016) \\
\hline Markov Model & 2 & $4.8 \%$ & (Patil and Thorat, 2016), (Huong et al., 2018) \\
\hline Bayesians Networks & 1 & $2.4 \%$ & (Alipio et al., 2017), (Joshi et al., 2017) \\
\hline ARIMA & 3 & $7.2 \%$ & (Park et al., 2017), (Santos et al., 2018), (Huong et al., 2018) \\
\hline Decision Tree & 1 & $2.4 \%$ & (Treboux and Genoud, 2018) \\
\hline Genetic Algorithm & 1 & $2.4 \%$ & (Janaszek, 2016) \\
\hline $\begin{array}{l}\text { Response Surface } \\
\text { Methodology }\end{array}$ & 1 & $2.4 \%$ & (Janaszek, 2016) \\
\hline BirdNet & 1 & $2.4 \%$ & (Fiehn et al., 2018) \\
\hline Lasso Regression & 1 & $2.4 \%$ & (Park et al., 2017) \\
\hline
\end{tabular}

Source: author 


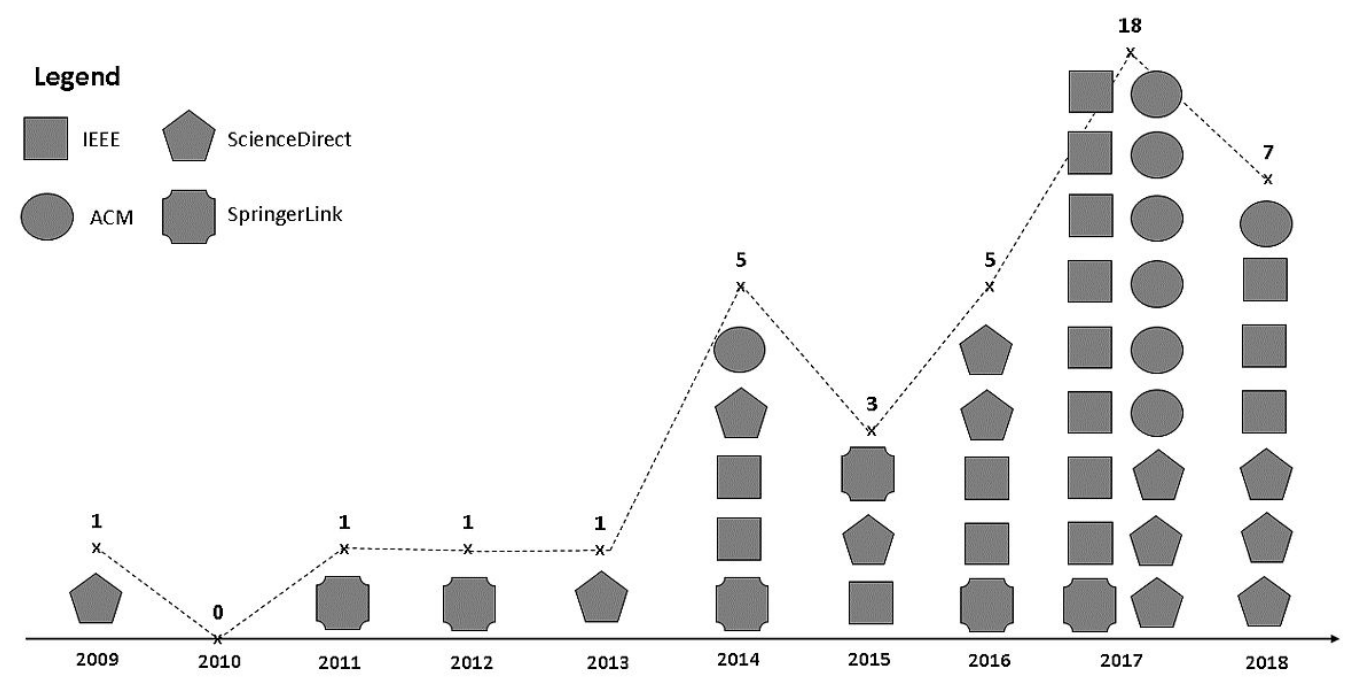

Source: author

Figure 2: Number of publications from 2009 to 2018.

\section{Threats to the validity of work}

Systematic mapping works are exposed to risks that may invalidate the study. These risks may arise from erroneously decisions taken during systematic mapping. In order to guarantee better results, four databases were selected, each of them known in the academic area for their relevance in computer science and similar areas. Therefore, it was sought to mitigate the possibility of databases impacting the results.

Five main terms were classified as a primary term and four secondary terms. Their synonyms were used to construct the search string. As a result of the string, we sought to obtain studies that related to one of the four secondary terms related to the primary term "Agriculture" and its specific areas "Hydroponics" and "Aquaponics". Thus, it was sought to obtain the largest number of studies in the search results.

The mapping did not consider conceptual aspects of the area of Agriculture, such as studies applied only in the field of natural sciences, focusing exclusively on the application of Agriculture involving the secondary terms "Prediction", "Context Awareness", "Cyber-Physical Systems" and "Internet of Things". This decision contributed to the filtering, directing the search only to a specific context within the area of "Agriculture and Computer Science", a discipline that concentrates a large amount of academic work.

The filtering process may have restricted the work so that some relevant studies may have been removed. To mitigate this risk, the filtering process was based on a technique widely adopted in academic works of systematic mapping (Petersen et al., 2015). The used revision processes were already applied by other authors (Dias et al, 2018; Bischoff et al., 2018; Dalmina et al., 2019).

\section{Discussion}

Only 16 studies used prediction in agriculture, that is, $38.1 \%$ of the articles. Among them, the most used technique was Neural Networks in five articles (Athani and Tejeshwar, 2017; Rodríguez et al., 2017; Park et al., 2017; Mehra et al., 2018; Plazas et al., 2018). The ARIMA and Linear/Vector Regression techniques were used each in three studies. Linear/Vector Regression was used in the studies of Rodríguez et al. (2017), Sarangdhar et al. (2017) and Goapa et al. (2018). On the other hand, ARIMA was used in the studies of Park et al. (2017), Santos et al. (2018) and Huong et al. (2018).

The use of image processing to capture information of pictures has increased in recent years and with that more systems and software related to Agriculture are able to use them. The information may have different purposes such as detecting plant species (Kumar et al., 2016), bird species (Fiehn et al., 2018), plant size (Joshi et al., 2017), (Fukatsu, 2014), fruit color (Tan et al., 2016), plagues on fruits (Tan et al., 2016) and also to count insects (Fukatsu, 2014). These applications show the potential in the area because of the diversity of information that can be obtained with the same equipment. Helfer et al. (2019) showed that studies already used large amounts of Wireless Sensors Networks (WSN) this aspect was also detected in this mapping. Another point in common between this study and that 
of Helfer et. al, 2019 was the use of the soil moisture sensor in most systems for automatic irrigation.

Analyzing the entire filtering process presented in Figure 1, and the Statistical Question 1 (STQ 1) that presents in which databases the articles were published, it is possible to verify that the most accurate databases that processed the query string were the ACM Library and IEEE Xplore, because they had a small number of articles in the initial survey, but have a relatively high number when compared to the total articles used in the mapping. The least accurate database was Science Direct, because of the 6042 papers resulting from the initial research, only 11 studies were used after the last filtering.

Another statistic was that by 2013 the amount of annual work on prediction and context awareness in agriculture remained stable, with up to one publication per year. From 2014, there was a progressive increase until 2018. In 2014, 5 works were published, in 2015 had a decrease ( 3 works) and in 2016 the number went back to 5 publications. However, there has been a great increase in publications in the last two years, showing the growing interest of researchers in this area.

\section{Conclusion}

The systematic mapping study presented the state of the art in the use of prediction and/or context awareness in Agriculture. This work also presented the main technologies used to obtain information, such as micro controllers. Also, it was found that various sensors are used to obtain planting information. In addition to the used sensors, it was also informed of the way used to send the obtained information regarding the crops to the servers in the studied articles. Besides presenting which works used cameras to obtain crop information, it was also possible to generate statistical data of the publications referring to the researched themes in the last decade.

Zewge and Dittrich (2017) indicated the problem of no integration between projects and suggested the creation of an integrated project that would allow the exchange of information not only between developers, but also between farmers. This mapping showed that many studies applied the same methodology as the usage of sensors to obtaining and analyze the gathered data. It is highlighted that 16 of the articles present the development of a predictive system. Therefore, some studies become repetitive regarding methodology, but there is a great diversity of prediction techniques applied in each of them, as shown in Table 7 . A challenge for future works is to deepen the studies and classify them into similar projects, which can make the use of prediction faster and provide better results. Another strategic future work will be the extension of this mapping through the evaluating of the relevance of publishing sources, for example, considering the rank of the journal or the total number of paper citations.

The use of mathematical and statistical algorithms to prove the efficacy of the work is present in the works that used prediction in Agriculture (Shahriar and Mcculluch, 2014; Patil and Thorat, 2016; Janaszek, 2016; Joshi et al., 2017; Alipio et al., 2017; Athani and Tejeshwar, 2017; Rodríguez et al., 2017; Sarangdhar et al., 2017; Park et al., 2017; Santos et al., 2018; Goap et al., 2018; Mehra et al., 2018; Plazas et al., 2018; Huong et al., 2018; Treboux and Genoud, 2018; Fiehn et al., 2018). These studies sought to show the result and the uncertainty when working with prediction, not being able to guarantee the occurrence of a certain event, although giving indications of situations that can improve the production due to the data analyzed.

A review of the work that has been published in the last decade may provide initial insights for new studies based on a prediction or, more specifically, prediction based on context awareness. Future studies can be carried out to comparison between the results obtained in the works that use prediction to determine which technique is being most effective in Agriculture. This effectiveness in agriculture can be achieved through a higher production yield in the same growing space, use of less manual labor, more automated systems, among other improvements.

Another point to be studied is the analysis of sensor types that make the prediction more effective, for example, the use of soil moisture and water's $\mathrm{pH}$ sensors, in order to determine which information would be most relevant to the prediction. With this, prediction can provide inferences with greater precision aiming at decision support systems, among other aids that the prediction can provide.

\section{Acknowledgments}

This study was financed in part by the Coordenação de Aperfeiçoamento de Pessoal de Nível Superior - Brasil (CAPES) - Finance Code 001, Fundação de Amparo à Pesquisa do Estado do Rio Grande 
do Sul - Fapergs/Brasil (http://www.fapergs.rs.gov. br), and Conselho Nacional de Desenvolvimento Científico e Tecnológico - CNPq/Brasil (http://www.cnpq.br). We would also like to thank the University of Vale do Rio dos Sinos - Unisinos (http://www.unisinos.br).

Corresponding authors

Bruno Guilherme Martini

Applied Computing Graduate Program, University of Vale do Rio dos Sinos, UNISINOS

São Leopoldo, Brazil

Phone: +55 51 999930710,E-mail: brunogui92@gmail.com

\section{References}

[1] Alipio, M. I., Earl, A., Dela Cruz, M., Doria, J. D. A., and Fruto, R. M. S. (2017) “A Smart Hydroponics Farming System Using Exact Inference in Bayesian Network", $6^{\text {th }}$ Global Conference on Consumer Electronics (GCCE 2017), pp. 2-6. ISBN 978-1-5090-4045-2. DOI 10.1109/GCCE.2017.8229470.

[2] Arakeri, M. P., Barsaiya, V. K. B. P. and Sairam, H. V. (2017) “Computer Vision Based Robotic Weed Control System for Precision Agriculture", International Conference on Advances in Computing, Communications and Informatics (ICACCI), pp. 1201-1205. ISBN 978-1-5090-6367-3. DOI 10.1109/ICACCI.2017.8126005.

[3] Athani, S., Tejeshwar, C. H. (2017) "Soil moisture monitoring using IoT enabled arduino sensors with neural networks for improving soil management for farmers and predict seasonal rainfall for planning future harvest in North Karnataka - India“, International conference on I-SMAC (IoT in Social, Mobile, Analytics and Cloud) (I-SMAC), pp. 43-48. ISBN 978-1-5090-3243-3. DOI 10.1109/I-SMAC.2017.8058385.

[4] Bischoff, V., Oliveira, K. S. F., Gonçales, L. J. and Barbosa., J. L. V. (2018) "Integration of Feature Models: A Systematic Mapping Study“, Information and Software Technology, pp. 1-30. ISSN 0950-5849. DOI 10.1016/j.infsof.2018.08.016.

[5] Carrasquilla-Batista, A., Chacón-Rodrígues, A., Solórzano-Quintana, M. (2016) “Using IoT resources to enhance the accuracy of overdrain measurements in greenhouse horticulture", CONCAPAN, pp. 1-5. ISBN 978-1-4673-9578-6. DOI 10.1109/CONCAPAN.2016.7942345.

[6] de la Concepcion, R. A, Stefanelli, R. and Trinchero, D. (2014) “A Wireless Sensor Network Platform Optimized for Assisted Sustainable Agriculture“, Global Humanitarian Technology Conference, pp. 159-165. ISBN 978-1-4799-7193-0. DOI 10.1109/GHTC.2014.6970276.

[7] Dalmina, L., Barbosa, J. L.V., Vianna, H. D. (2019) “A systematic mapping study of gamification models oriented to motivational characteristics", Behaviour \& Information Technology, Vol. 38, No. 11, p. 1-18. ISSN 1362-3001. DOI 10.1080/0144929X.2019.1576768.

[8] Dey, A. K., Abowd, G. D. and Salber, D. A. (2001) “A Conceptual Framework and a Toolkit for Supporting the Rapid Prototyping of Context-aware Applications", Human-Computer Interaction, Vol. 16, No. 2, pp. 97-166. ISSN 1532-7051. DOI 10.1207/S15327051HCI16234_02.

[9] Dias, L. P. S., Barbosa, J. L. V. and Vianna, H. D. (2018) "Gamification and serious games in depression care: A systematic mapping study“, Telematics and Informatics, Vol. 35, No. 1, pp. 213-224. ISSN 0736-5853. DOI 10.1016/j.tele.2017.11.002.

[10] Divya, P., Sonkiya, S., Das, P., Manjusha, V. V. and Ramesh, M. V. (2014) "CAWIS: Context Aware Wireless Irrigation System“, International Conference on Computer, Communication, and Control Technology (I4CT), pp. 310-315. ISBN 978-1-4799-4555-9. DOI 10.1109/I4CT.2014.6914195.

[11] Eko, R., Sisyanto, N. and Kurniawan, N. B. (2017) "Hydroponic Smart Farming Using Cyber Physical Social System with Telegram Messenger", International Conference on Information Technology Systems and Innovation (ICITSI), pp. 239-245. ISBN 978-1-5386-3100-3. DOI 10.1109/ICITSI.2017.8267950. 
[12] Fiehn, H. B., Schiebel, L., Avila, A. F., Miller, B. and Mickelson, A. (2018) "Smart Agriculture System Based on Deep Learning", $2^{\text {nd }}$ International Conference on Smart Digital Environment (ICSDE), pp.158-165. ISBN 978-1-4503-6507-9.

[13] Fukatsu, T. (2014) "Web-based sensor network system 'Field Servers' for practical agricultural applications", International Workshop on Web Intelligence and Smart Sensing (IWWISS), pp. 01-08. ISBN 978-1-4503-2747-3. DOI 10.1145/2637064.2637090.

[14] Goap, A., Sharmab, D., Shuklab, A. K. and Krishna, C. R. (2018) "An IoT based smart irrigation management system using Machine learning and open source technologies", Computers and Electronics in Agriculture, Vol. 155, pp. 41-49. ISSN 0168-1699. DOI 10.1016/j.compag.2018.09.040.

[15] Helfer, G. A., Barbosa, J. L. V., Martini, B. G., dos Santos, R. B. and da Costa A. B.(2019) "Ubiquitous Computing in Precision Agriculture: A Systematic Review", AGRIS on-line Papers in Economics and Informatics, Vol. 11, No. 4, pp. 3-13. ISSN 1804-1930. DOI 10.7160/aol.2019.110401.

[16] Huong, T. T., Thanh, N. H., Thi, N. and Marshall, A. (2018) "Water and Energy-Efficient Irrigation based on Markov Decision Model for Precision Agriculture", IEEE Seventh International Conference on Communications and Electronics (ICCE), pp. 51-56. ISBN 978-1-5386-3679-4. DOI 10.1109/CCE.2018.8465723.

[17] Ivanov I. and Tsvetkov, V. (2017) "Intelligent Planting", International Conference on Computer Systems and Technologies (CompSysTech'17), pp. 265-271. ISBN 978-1-4503-5234-5. DOI 10.1145/3134302.3134328.

[18] Jacob, N. K. (2017) "IoT Powered Portable Aquaponics System", Proceedings of the Second International Conference on Internet of things, Data and Cloud Computing (ICC), pp. 0-5. ISBN 978-1-4503-4774-7. DOI 10.1145/3018896.3018965.

[19] Joshi, J., Polepally, S., Kumar, P., Samineni, R., Rahul, S. R., Sumedh, K., Tej, D. G. K. and Rajapriya, V. (2017) "Machine Learning Based Cloud Integrated Farming", International Conference on Machine Learning and Soft Computing, pp. 1-6. ISBN 978-1-4503-4828-7. DOI 10.1145/3036290.3036297.

[20] Kokkonis, G., Kontogiannis, S. and Tomtsis, D. (2017) "FITRA - A Neuro-fuzzy computational algorithm approach based on an embedded water planting system", International Conference on Internet of things, Data and Cloud Computing (ICC), pp. 0-7. ISBN 978-1-4503-4774-7. DOI 10.1145/3018896.3018934.

[21] Kubicek, P., Kozel, J., Stampach, R. and Lukas, V. (2013) "Prototyping the visualization of geographic and sensor data for agriculture“, Computers and Electronics in Agriculture, Vol. 97, pp. 83-91. ISSN 0168-1699. DOI 10.1016/j.compag.2013.07.007.

[22] Kumar, S., Gogul, I., Raj., D., Pragadesh, S. K. and Sarathkumar, S. (2016) "Smart Autonomous Gardening Rover with Plant Recognition using Neural Networks", International Conference On Advances In Computing \& Communications (ICACC), Vol. 93, pp. 975-981. ISSN 1877-0509. DOI 10.1016/j.procs.2016.07.289.

[23] López-Riquelme, J. A., Pavón-Pulido, N., Navarro-Hellín, H., Soto-Valles, F. and Torres-Sáncheza, R. (2017) "A software architecture based on FIWARE cloud for Precision Agriculture", Agriculture Water Management, Vol. 183, pp. 123-135. ISSN 0378-3774. DOI 10.1016/j.agwat.2016.10.020.

[24] Luimula, M., Shelby, Z., Tervonen, J., Markkula, J., Weckström, P. and Verronen, P. (2009) "Developing Geosensor Network Support for Locawe Platform - Application of Standards in Low-Rate Communication Context", International Conference on Pervasive Services, pp. 73-82. ISBN 978-1-60558-644-1. DOI 10.1145/1568199.1568211.

[25] Ma, J., Li, X., Wen, H., Fu, Z. and Zhang, L. (2015) “A key frame extraction method for processing greenhouse vegetables production monitoring video", Computers and Electronics in Agriculture, Vol. 111, pp. 92-102. ISSN 0168-1699. DOI 10.1016/j.compag.2014.12.007. 
[26] Manzatto, C. V., Bhering, S. B. and Simões, M. (1999) "Agricultura de precisão: propostas e ações da Embrapa solos. EMBRAPA Solos", EMBRAPA Solos., Jun. 1999. [Online] Available: http://www.cnps.embrapa.br/search/pesqs/proj01/proj01.html [Acessed: 10 Sep. 2019].

[27] Mehra, M., Saxena, S., Sankaranarayanan, S., Tom, R. J.and Veeramanikandan, M. (2018) "IoT based hydroponics system using Deep Neural Networks", Computers and Electronics in Agriculture, Vol. 155, pp. 473-486. ISSN 0168-1699. DOI 10.1016/j.compag.2018.10.015.

[28] Nagini, S., Rajini Kanth, T. V. and Kiranmayee, B. V. (2016) "Agriculture yield prediction using predictive analytic techniques", International Conference on Contemporary Computing and Informatics (IC3I). ISBN 978-1-5090-5256-1. DOI 10.1109/IC3I.2016.7918789.

[29] Park, J., Choi, J., Lee, Y. and Min, O. (2017) "A Layered Features Analysis in Smart Farm Environments", Proceedings of the International Conference on Big Data and Internet of Thing (BDIOT), pp. 169-173. ISBN 978-1-4503-5430-1. DOI 10.1145/3175684.3175720.

[30] Patil S. S. and Thorat, S. A. (2016) "Early Detection of Grapes Diseases Using Machine Learning and IoT", Second International Conference on Cognitive Computing and Information Processing (CCIP). ISBN 978-1-5090-1025-7. DOI 10.1109/CCIP.2016.7802887.

[31] Petersen, K., Vakkalanka, S. and Kuzniarz, L. (2015) "Guidelines for conducting systematic mapping studies in software engineering: An update“, Information and Software Technology, Vol. 64, pp. 1-18. ISSN 0950-5849. DOI 10.1016/j.infsof.2015.03.007.

[32] Pimentel, D., Berger, B., Filiberto, D., Newton, M., Wolfe, B., Karabinakis, E., Clark, S., Poon, E., Abbett, E. and Nandagopal, S. (2004) "Water resources: agricultural and environmental issues“, $\quad$ BioScience, $\quad$ pp. $\quad 909-918 . \quad$ ISSN $0006-3568$. DOI 10.1641/0006-3568(2004)054[0909:WRAAEI]2.0.CO;2.

[33] Plazas, J. A. P., Gaona-García, P. A. and Marin, C. E. M. (2018) "Proposal of a computational intelligence prediction model based on Internet of Things technologies", IEEE International Conference on Smart Internet of Things, pp. 186-191. ISBN 978-1-5386-8543-3. DOI 10.1109/SmartIoT.2018.00041.

[34] Popovic, T., Latinovic', N., Pešic', A., Zecevic', Z., Krstajic', B. and Djukanovic', S. (2017) "Architecting an IoT-enabled platform for precision agriculture and ecological monitoring: A case study", Computers and Electronics in Agriculture, Vol. 140, pp. 255-265. ISSN 0168-1699. DOI 10.1016/j.compag.2017.06.008.

[35] Rajendrakumar, S., Rajashekarappa, Parvati, V. K., Parameshachari, B. D., Sunjiv Soyjaudah, K. M. and Banu, R. (2017) "An Intelligent Report Generator for Efficient Farming", International Conference on Electrical, Electronics, Communication, Computer and Optimization Techniques (ICEECCOT). ISBN 978-1-5386-2361-9. DOI 10.1109/ICEECCOT.2017.8284640.

[36] Rodríguez, S., Gualotuña, T. and Grilo, C. (2017) "A System for the Monitoring and Predicting of Data in Precision Agriculture in a Rose Greenhouse Based on Wireless Sensor Networks", Procedia Computer Science. Vol. 121, pp. 306-313. ISSN 1877-0509. DOI 10.1016/j.procs.2017.11.042.

[37] Rupanagudi, S. R., Ranjani, B. S., Prathik Nagarj, Bhat, V. G. and Thippeswamy, G. (2015) "A Novel Cloud Computing based Smart Farming System for Early Detection of Borer Insects in Tomatoes“, International Conference on Communication, Information \& Computing Technology (ICCICT). ISBN 978-1-4799-5522-0. DOI 10.1109/ICCICT.2015.7045722.

[38] Saha, S., Paul, S., Halder, S. and Majumder, K. (2017) "Smart Agricultural System : Better Accuracy and Productivity“, Devices for Integrated Circuit (DevIC), pp. 23-24. ISBN 978-1-5090-4724-6. DOI 10.1109/DEVIC.2017.8073960.

[39] Santos, U. J. L., Pessin, G., da Costa, C. A., da Rosa Righi, R. (2018) "AgriPrediction: A proactive internet of things model to anticipate problems and improve production in agricultural crops", Computers and Electronics in Agriculture, Vol. 161, pp. 202-213. ISSN 0168-1699. DOI 10.1016/j.compag.2018.10.010. 
[40] Sarangdhar, A. A. and Pawar, P. V. R.(2017) "Machine Learning Regression Technique for Cotton Leaf Disease Detection and Controlling using IoT", International Conference on Electronics, Communication and Aerospace Technology (ICECA), pp. 449-454. ISBN 978-1-5090-5686-6. DOI 10.1109/ICECA.2017.8212855.

[41] Shahriar S. and Mcculluch, J. (2014) “A Dynamic Data-driven Decision Support for Aquaculture Farm Closure“, Procedia Computer Science, Vol. 29, pp. 1236-1245. ISSN 1877-0509. DOI 10.1016/j.procs.2014.05.111.

[42] Tan, L. (2016) "Cloud-based Decision Support and Automation for Precision Agriculture in Orchards", IFAC-PapersOnLine, Vol. 49, No. 16, pp. 330-335. ISSN 2405-8963. DOI 10.1016/j.ifacol.2016.10.061.

[43] Tan, W., Zhao, C. and Wu, H. (2016) "Intelligent alerting for fruit-melon lesion image based on momentum deep learning“, Multimed. Tools and Application, pp. 16741-16761. ISSN 1380-7501. DOI 10.1007/s11042-015-2940-7.

[44] Treboux, J. and Genoud, D. (2018) "Improved Machine Learning Methodology for High Precision Agriculture“, Global Internet of Things Summit (GIoTS), pp. 1-6. ISBN 978-1-5386-6451-3. DOI 10.1109/GIOTS.2018.8534558.

[45] Winiczenko, R., Górnicki, K., Kaleta, K. and Janaszek-Mańkowska, M. (2016) “Optimisation of ANN topology for predicting the rehydrated apple cubes colour change using RSM and GA“, Neural Computing \& Applications, Vol. 30, pp. 1795-1809. ISSN 0941-0643. DOI 10.1007/s00521-016-2801-y.

[46] Xu, D., Li, D., Fei, B., Wang, Y. and Peng, F. (2014) “A GPRS-Based Low Energy Consumption Remote Terminal Unit for Aquaculture Water Quality“, International Federation for Information Processing (IFIP).pp. 492-503. DOI 10.1007/978-3-642-54341-8_52.

[47] Yahata, S., Onishi, T., Yamaguchi, K., Ozawa, S., Kitazono, J., Ohkawa, T., Yoshida, T. and Muraka, N. (2017) "A Hybrid Machine Learning Approach to Automatic Plant Phenotyping for Smart Agriculture“, International Joint Conference on Neural Networks (IJCNN), pp. 1787-1793. ISSN 2161-4407. DOI 10.1109/IJCNN.2017.7966067.

[48] Zewge, A. and Dittrich, Y. (2017) "Systematic Mapping Study of Information Technology for Development in Agriculture (The Case of Developing Countries)“, Electronic Journal of Information Systems in Developing Countries (EJISDC), pp. 1-25. ISSN 1681-4835. DOI 10.1002/j.1681-4835.2017.tb00602.x.

[49] Zhang, P., Zhang, Q., Liu, F., Li, J. Cao, N. and Song, C. (2017) “The Construction of the Integration of Water and Fertilizer Smart Water Saving Irrigation System Based on Big Data“, International Conference on Computational Science and Engineering (CSE) and IEEE International Conference on Embedded and Ubiquitous Computing (EUC), pp. 392-397. ISBN 978-1-5386-3221-5. DOI 10.1109/CSE-EUC.2017.258.

[50] Zhou, B. and Li, L. (2017) "Security monitoring for intelligent water-saving precision irrigation system using cloud services in multimedia context", Multimedia Tools Applications, pp 1-15. ISSN 1380-7501.

[51] Zhou, L., Song, L., Xie, C. and Zhang, J. (2012) „Applications of Internet of Things in the Facility Agriculture“, In Li D., Chen Y. (eds) „Computer and Computing Technologies in Agriculture VI“, CCTA 2012. IFIP Advances in Information and Communication Technology, Vol 392. ISSN 1868-4238. DOI 10.1007/978-3-642-36124-1_36.

[52] Zhou, H., Liu, B. and Dong, P. (2011) “The Technology System Framework of the Internet of Things and Its Application Research in Agriculture, In Li D., Chen Y. (eds) Computer and Computing Technologies in Agriculture V. CCTA 2011, IFIP Advances in Information and Communication Technology, Vol 368. E-ISBN 978-3-642-27281-3, ISBN 978-3-642-27280-6. DOI 10.1007/978-3-642-27281-3_35. 